\title{
Lewis Acid Catalyzed Stereoselective Synthesis of Trisubstituted Tetrahydrofurans
}

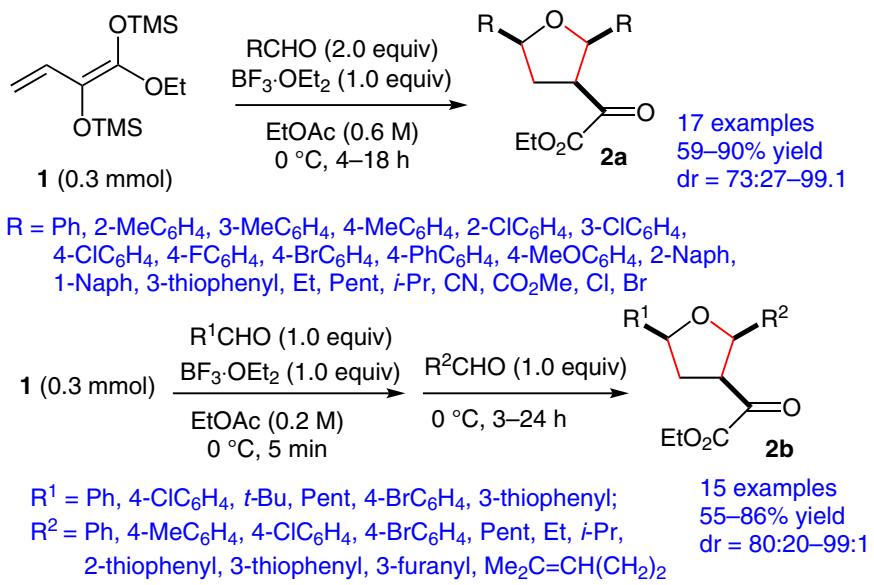

tetrahydrofurans

Significance: Reported is a Lewis acid $\left(\mathrm{BF}_{3} \cdot \mathrm{OEt}_{2}\right)$ catalyzed synthesis of 2,3,5-trisubstituted tetrahydrofurans 2a by the reaction of bis(silyloxy)diene $\mathbf{1}$ with aldehydes in good yields and with excellent stereoselectivity. The reaction involves a domino process in which three new $\sigma$-bonds and three stereogenic centers are produced. Tetrahydrofurans $\mathbf{2} \mathbf{b}$ with different 2 - and 5-substituents were obtained by using two different aldehydes through a sequential reaction $(\mathbf{1} \rightarrow \mathbf{2 b})$. Both aryl- and alkylsubstituted tetrahydrofurans were easily obtained, but there was a decrease in stereoselectivity when $\alpha$-branched aldehydes were used. Thienyl-substituted heterocycles showed a high tendency to isomerize; consequently, slightly lower dr values were observed. Single X-ray crystal analysis confirmed the 2,3,5-all-cis configuration of the compound $\mathbf{2 c}\left(\mathrm{R}^{1}=\mathrm{Ph} ; \mathrm{R}^{2}=4-\mathrm{BrC}_{6} \mathrm{H}_{4}\right)$. Tetrahydrofuran $\mathbf{2 d}\left(R^{1}=R^{2}=P h\right)$ underwent rapid epimerization on reaction with triethylamine to give the thermodynamically more favorable 2,3trans,2,5-cis diastereomer (yield 82\%, dr = 87:13).
Comment: The tetrahydrofuran heterocycle is a key scaffold in various natural products and medicinally active molecules (see Review below), and various methods are known for their synthesis (see, for example: B. List and co-workers J. Am. Chem. Soc. 2016, 138, 14538). However, these methods are limited to the use of the same aldehyde (2.0 equiv) resulting in equal 2 - and 5 -substitution of the tetrahydrofurans, and they provide racemic products. The reported method employs a diastereoselective one-pot synthesis of $\mathbf{2 a}$ and $\mathbf{2} \mathbf{b}$ from readily available substrates. A probable mechanism is proposed involving a vinylogous aldol reaction followed by a Prins-type cyclization (M. Boomhoff, C. Schneider Chem. Eur. J. 2012, 18, 4185). Two of the tetrahydrofuran products 2 were converted into bi- and tricyclic compounds by carbonyl-ene reactions (71-95\% yield; $d r=$ 80:20 to 95:5) (A. C. Jackson, B. E. Goldman, B. B. Snider J. Org. Chem. 1984, 49, 3988).

Review: A. de La Torre, C. Cuyamendous, V. Bultel-Poncé, T. Durand, J.-M. Galano, C. Oger Tetrahedron 2016, 72, 5003-5025. 